\title{
Respiratory complications of relapsing polychondritis
}

\author{
G. J. GIBSON and P. D A VIS \\ Department of Medicine, Royal Postgraduate Medical School, \\ Hammersmith Hospital, London W12
}

\begin{abstract}
Gibson, G. J. and Davis, P. (1974). Thorax, 29, 726-731. Respiratory complications of relapsing polychondritis. The respiratory function of a patient with relapsing polychondritis is described. He had severe airflow obstruction due to disease of both the extra and intrathoracic large airways. Evidence of small airways disease was lacking. The airflow obstruction was probably due to a combination of structural narrowing and an enhanced dynamic effect. Despite the severity of his disease the patient's exercise capacity was only slightly reduced but he developed carbon dioxide retention on exercise. Involvement of the airways is a common feature of this rare disease and demands full physiological and radiographic assessment if tracheostomy or other surgical procedure is contemplated.
\end{abstract}

Relapsing polychondritis, first described by Jaksch-Wartenhorst (1923), is a rare inflammatory disease affecting cartilage-containing tissues. The clinical features have been the subject of several reviews (Pearson, Kline, and Newcomer, 1960; Kaye and Sones, 1964; Dolan, Lemmon, and Teitelbaum, 1966; Hughes, Berry, Seifert, and Lessof, 1972; leading article; 1973); many tissues may be affected, including the nose, ears, costal cartilages, joints, and eyes. A poor prognostic feature is said to be involvement of the cartilage of the upper airway leading to 'collapse' of the larynx or trachea, and respiratory complications have accounted for most of the reported deaths. To avoid these complications early tracheostomy has been suggested but as there is little information on the extent of airway involvement, its value is uncertain. Neither is it established whether the airway 'collapse' is due to fixed obstruction or to abnormal dynamic effects in an airway whose compliance has been increased by destruction of cartilage. Assessment of both these factors is clearly important if any attempt at surgical replacement or support of the diseased airway is contemplated. Accounts of pulmonary function in this condition are few and usually limited to spirometric measurements. We here present the results of investigation of a patient with relapsing polychondritis in whom respiratory symptoms were prominent.

\section{CASE REPORT}

A 36-year-old non-smoking Iranian developed cough, mucoid sputum, attacks of 'bronchospasm', and $\mathbb{\perp}$ pyrexia in March 1972. He was treated initially as a $\overrightarrow{\vec{P}}$ case of 'asthmatic bronchitis' but failed to respond to antibiotics and bronchodilators. By June 1972 his respiratory symptoms had progressed and he had developed expiratory stridor. He had lost $12 \mathrm{~kg}$ in weight and complained of pain in the nasal cartilage and manubriosternal joint. A clinical diagnosis of relapsing polychondritis was made and he was treated with prednisone.

In December 1972 the patient was referred to the Hammersmith Hospital. On examination he was pyrexial and showed the characteristic facies of the disease with flattening of the bridge of the nose; there was tenderness and hypermobility of the nasal and aural cartilages and tenderness of the rib cartilages and trachea. Examination of the chest showed tachypnoea, bovine cough, and low-pitched expiratory N stridor; the lung fields were otherwise clear on auscultation. Examination of the cardiovascular system, $N$ abdomen, and central nervous system was negative; there was no evidence of involvement of the joints or eyes.

INVESTIGATIONS Haemoglobin $14.5 \mathrm{~g} / 100 \mathrm{ml}$. White cell count $6,000 / \mathrm{mm}^{3}$, film normal. ESR $77 \mathrm{~mm}$ in first hour (Westergren). Total serum protein $6.6 \mathrm{~g} /$ $100 \mathrm{ml}$; albumin $3 \cdot 3 \mathrm{~g} / 100 \mathrm{ml}$; globulin $3 \cdot 3 \mathrm{~g} / 100 \mathrm{ml}$. Electrophoretic pattern-increased $\alpha_{1}$ and $\alpha_{2}$ globulins. Immunoglobulins normal. Wassermann reaction nega- 
tive. Rose Waaler, latex, and antinuclear factor negative. Human fetal cartilage antibody strongly positive. Electrocardiogram normal.

A chest radiograph showed normal lung fields with narrowing of the trachea and main bronchi, which was more evident on tomography (Fig. 1).

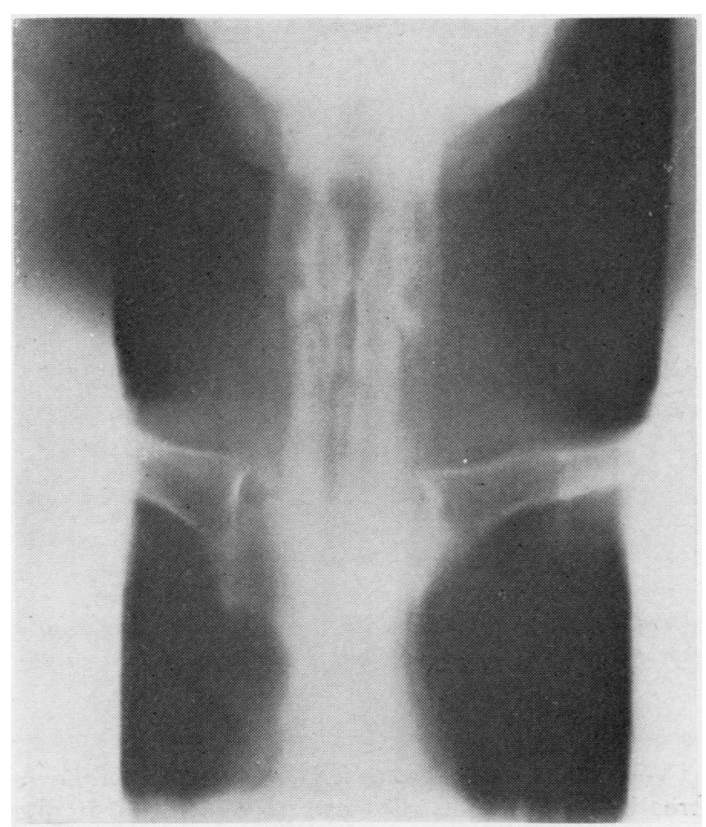

FIG. 1. Tomogram of larynx and trachea showing extensive narrowing. Film taken during breath holding in inspiration. The lower trachea and main bronchi showed similar changes.

RESPIRATORY FUNCTION Measurements of lung volumes, specific airways conductance, transfer factor (single-breath method), and resting arterialized ear lobe capillary blood gases are shown in Table $I$ and are compared with predicted values. There was a greatly reduced one-second forced expiratory volume $\left(F E V_{1}\right)$ and a normal vital capacity (VC) together

T A B L E I

RESPIRATORY FUNCTION AT REST

\begin{tabular}{|c|c|c|}
\hline & Measured & Predicted \\
\hline $\begin{array}{l}\text { Lung volumes (litres) } \\
\text { FEV }_{1} \\
\text { FIV } \\
\text { Vital capacity } \\
\text { Total lung capacity } \\
\text { Residual volume } \\
\text { Specific airways conductance } \\
\left.\text { (sec-1 } \mathrm{cmH}_{2} \mathrm{O}^{-1}\right) \\
\text { Transfer factor (ml min }{ }^{-1} \mathrm{mmHg}^{-1} \\
\text { Arterialized blood gases } \\
\mathrm{PO}_{2} \text { (mmHg) } \\
\text { PCO }_{2} \text { (mmHg) }\end{array}$ & $\begin{array}{l}0 \cdot 8 \\
1 \cdot 5 \\
4 \cdot 1 \\
6 \cdot 0 \\
1 \cdot 9 \\
0 \cdot 03 \\
40 \cdot 0 \\
93 \\
39\end{array}$ & $\begin{array}{c}3.7 \\
>\quad 3.7 \\
4.4 \\
6.2 \\
1.8 \\
>\quad 0.13 \\
30.1\end{array}$ \\
\hline
\end{tabular}

with a low airways conductance, indicating severe airflow obstruction. The one-second forced inspiratory volume $\left(\mathrm{FIV}_{1}\right)$ was also low but greater than the $\mathrm{FEV}_{\mathbf{1}}$; static lung volumes, transfer factor, and blood gases at rest were all normal.

Maximum expiratory and inspiratory flow-volume curves are shown in Fig. 2 with normal curves for comparison. The recording showed unusually wide oscillation of expiratory flow rate corresponding to the expiratory stridor. No similar oscillation occurred on inspiration. Maximum flow rates throughout the vital capacity were reduced but the reduction was considerably greater on expiration than inspiration.

'Closing volume' was measured by the argon bolus technique (McCarthy and Milic-Emili, 1973) and a representative example of the expired argon trace measured by a mass spectrometer is shown (Fig. 3). The ratio of 'phase IV' to VC was $17 \%$ which is normal for the patient's age (Maberly and Freedman, unpublished). A second noteworthy feature of the trace was the near horizontal alveolar plateau ("phase III'), indicating even emptying of lung units.

Exercise tolerance was assessed by progressive exercise on a bicycle ergometer, the power output being increased by $100 \mathrm{kpm} \mathrm{min} \mathrm{min}^{-1}$ each minute. The patient comfortably achieved a power output of $700 \mathrm{kpm} \mathrm{min}^{-1}$ which represents only a mild reduction of exercise capacity for his age. At this level his ventilation was $27 \mathrm{l} . \mathrm{min}^{-1}$ which is very close to his predicted maximum breathing capacity $\left(\mathrm{FEV}_{1} \times 35\right.$; Gandevia and Hugh-Jones, 1957). Further analysis of the patient's excercise response and pulmonary gas exchange was obtained by steady-state exercise at a power output of $350 \mathrm{kpm} \mathrm{m^{-1 }}$ with sampling of ear lobe capillary blood. The results are compared with values at rest in Table II. The most striking abnormality on exercise was the rise in arterial $\mathrm{CO}_{2}$ tension from 39 to $50 \mathrm{mmHg}$, indicating alveolar underventilation. The mixed expired $\mathrm{CO}_{2}$ tension was high and total ventilation correspondingly low. The arterial oxygen tension fell from 93 to $86 \mathrm{mmHg}$ but the alveolar-arterial oxygen tension difference and calculated physiological shunt remained normal. This,

T A B L E I I

RESPONSE TO EXERCISE

\begin{tabular}{|c|c|c|}
\hline & Rest & $\begin{array}{l}\text { Exercise } \\
350 \mathrm{~K} \text { pm min } \\
\text { (58 watts) }\end{array}$ \\
\hline 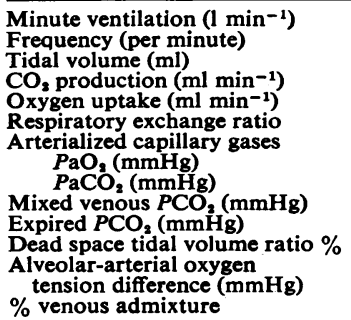 & $\begin{array}{l}13 \cdot 0 \\
25 \\
520 \\
366 \\
416 \\
0 \cdot 88 \\
93 \\
39 \\
51 \cdot 5 \\
24 \cdot 4 \\
26 \\
13 \\
\end{array}$ & $\begin{array}{c}21 \cdot 9 \\
21 \\
1042 \\
1090 \\
1165 \\
0 \cdot 94 \\
86 \\
50 \\
72 \cdot 5 \\
43 \cdot 2 \\
8 \\
11 \\
2 \cdot 2\end{array}$ \\
\hline
\end{tabular}



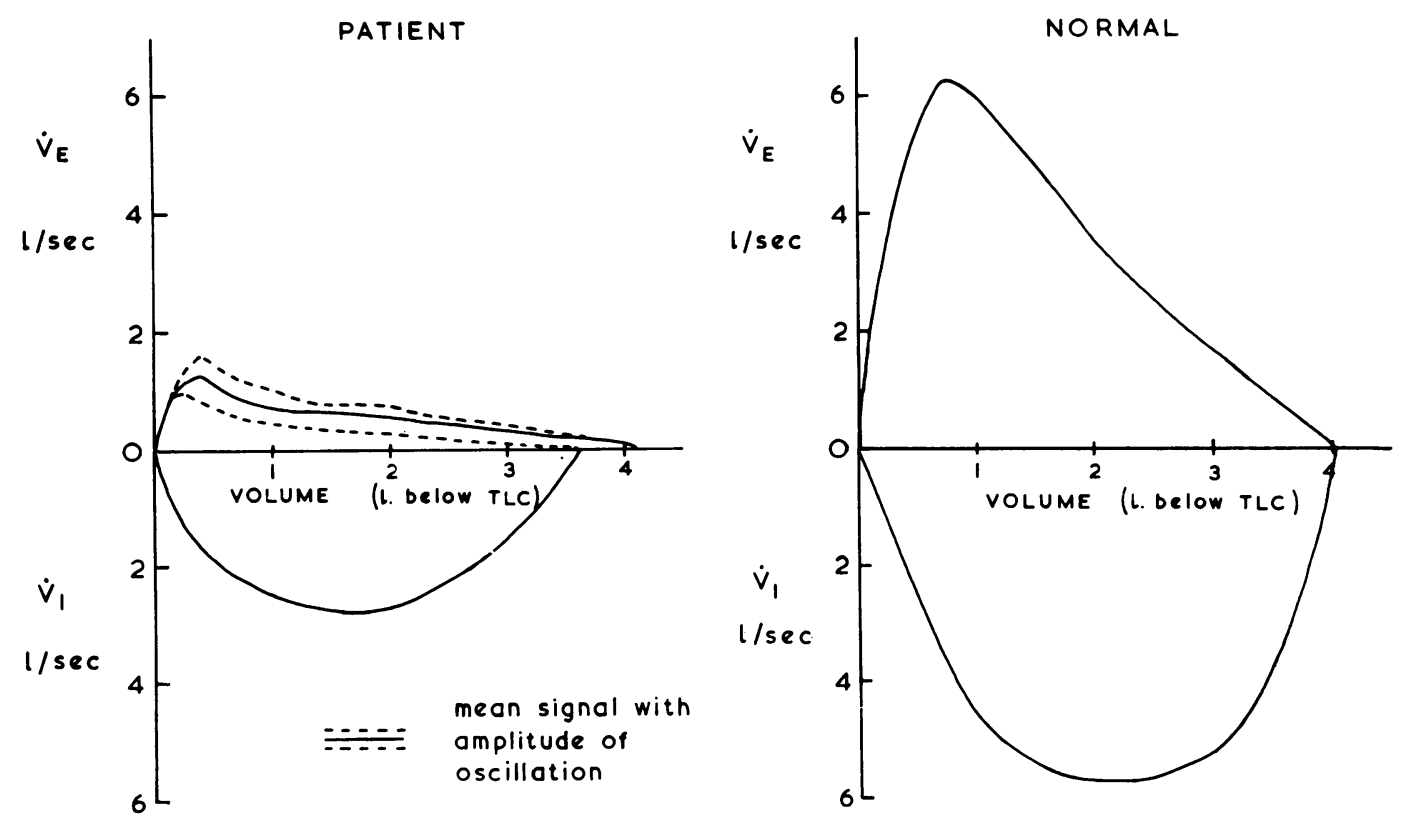

FIG. 2. Maximum expiratory and inspiratory flow-volume curves of the patient with normal curves for comparison. Expiratory curve obtained by forced vital capacity manoeuvre from full 'inflation. Inspiratory curve obtained after slow expiration to residual volume.

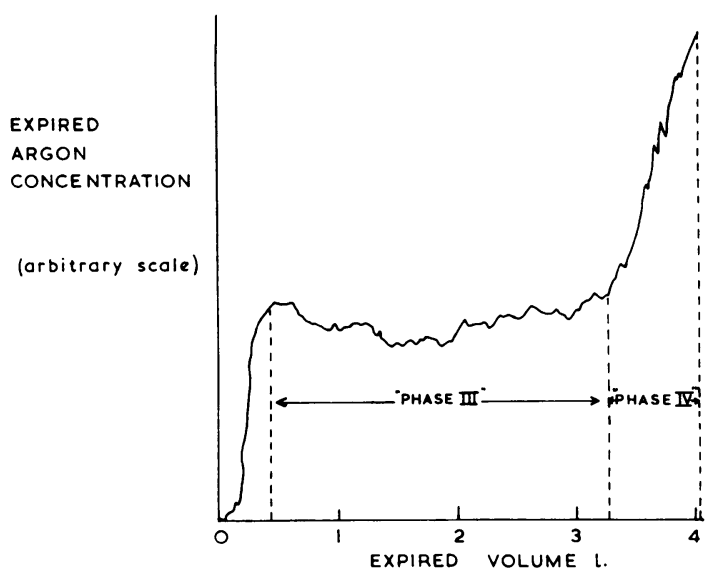

FIG. 3. Expired argon trace during slow expiration from total lung capacity to residual volume. ( $A$ bolus of argon had been injected at the mouth while the patient held his breath at residual volume and a slow full inspiration preceded the recording.) The point of inflexion between phases III and IV marks the 'closing volume'.

together with the normal physiological dead space, indicates normal matching of ventilation and perfusion.
Ventilatory response to $\mathrm{CO}_{2}$ measured by the rebreathing technique of Read (1967) was 0.56 litre $\overrightarrow{\vec{O}}$ $\mathrm{min}^{-1} \mathrm{mmHg}^{-1}$ which is at the lower limit of the wide 3 normal range quoted by Rebuck and Read (1971).

\section{DISCUSSION}

The aetiology of relapsing polychondritis remains obscure. Though inflammation is localized in tissues with high glycosoaminoglycan concentra- 3 . tion there is little evidence that the disease is pri- $\delta$ marily a disorder of metabolism. The occasional association with aortitis, iritis, and vasculitis $ᄋ$ supports the more widely held view that it is related to the connective tissue diseases. There may be an autoimmune basis: chondroitin sulphate has been shown to produce a humoral or antibody response in rabbits (Glynn and Hol- N borow, 1952) and lymphocyte transformation has been induced with chondromucoprotein in some patients (Herman and Hess, 1971). In addition, antibodies to fetal human cartilage were found in two of the three cases reported by Hughes et al. @्? (1972). None of these findings, however, is specific 0 for relapsing polychondritis.

Of the typical features of the disease, our $\frac{\mathbb{D}}{\mathrm{D}}$ patient showed inflammation of nasal, aural, and $\mathbb{D}$ costal cartilages and antibodies in the serum to $\frac{\circ}{0}$ 
fetal cartilage. However, the most important, and potentially lethal, complication was involvement of the airways. Our studies of respiratory function were aimed at assessing (1) the severity of the airflow obstruction, (2) its site and extent, (3) its nature, i.e., whether due to fixed obstruction or to abnormal dynamic effects, and (4) the degree of impairment of the patient's exercise capacity and the pattern of his response to exercise.

The degree of airflow obstruction, as judged by the $\mathrm{FEV}_{1}$ and conductance, was severe and there was no improvement after bronchodilator. Though there was radiological evidence of abnormality of the extrathoracic trachea, the FIV $_{1}$ and inspiratory flow rates were reduced less than the expiratory measurements, the typical pattern of intrathoracic airways obstruction (Miller and Hyatt, 1969; Clark, 1970).

The radiological and functional studies together show evidence of narrowing of at least the larger intrathoracic airways. However, the indices of gas exchange such as the expired gas trace, alveolar arterial oxygen tension difference, and transfer factor, were normal. This is quite unlike the usual forms of intrathoracic airflow obstruction-chronic bronchitis, asthma or emphysemawhere the disease process is probably maximal in smaller airways of $2 \mathrm{~mm}$ diameter or less. Though cartilage in the normal bronchial tree is present in airways down to $1 \mathrm{~mm}$ diameter (Bates, Macklem, and Christie, 1971) it is of less importance for bronchial stability in these smaller intrapulmonary airways which are supported by surrounding lung, and its loss should produce little effect on pulmonary function. The few necropsy studies of the airways in relapsing polychondritis show, however, in addition to loss of cartilage, areas of extensive narrowing and distortion with granulation tissue and fibrosis (e.g., Harwood, 1958). Though the pathological evidence is confined to the larger airways, one would expect similar changes in smaller airways considerably to affect pulmonary gas exchange and produce abnormalities of the alveolar-arterial oxygen tension difference or the 'alveolar' plateau on the expired gas trace. The normality of these tests in our patient makes it unlikely that the disease extends far beyond the main bronchi. This could have been further assessed by bronchoscopic studies but these were thought to be potentially hazardous to our patient and were not performed.

The emphasis of various authors on 'collapse' of the trachea in relapsing polychondritis has perhaps implied that the airflow obstruction is a dynamic effect due to loss of rigidity of the airway walls. However, our patient's low specific conductance, which is measured during panting, reflects an abnormally high resistance of the airways at low flow rates and together with the radiographs indicates severe 'intrinsic' narrowing. More sophisticated studies, including intraluminal pressure measurements, would be required to establish whether in addition dynamic narrowing of the large intrathoracic airways was excessive and to determine whether this was secondary to peripheral obstruction or to enhanced compliance of the central airways. A cine film of the major airways did, however, appear to show an abnormal dynamic effect even during tidal breathing, which, in view of the probable normality of the peripheral airways, supports the concept of increased compressibility of the affected large airways.

The patient's response to exercise was unusual; by allowing the arterial $\mathrm{CO}_{2}$ tension to rise he was able to achieve a surprisingly high level of exercise at a low ventilation. The rise of $11 \mathrm{mmHg}$ is greater than is usually seen in chronic bronchitis (Spiro, Hahn, Edwards, and Pride, 1975); it was accompanied by only a slight fall in arterial oxygen tension and, unlike chronic bronchitis, there was no evidence of ventilation/perfusion inequality. It is interesting that alveolar underventilation occurs on exercise in normal subjects breathing through an external resistance (Gee, Burton, Vassallo, and Gregg, 1968) and Al-Bazzaz and Kazemi (1972) have reported slight alveolar underventilation as the response to exercise in patients with upper (extrathoracic) airway obstruction; perhaps this pattern is characteristic of obstruction of the larger airways. Our patient's apparent insensitivity to $\mathrm{CO}_{2}$ is confirmed by the low ventilatory response during rebreathing. This does not necessarily indicate insensitivity of the respiratory centre but is more likely a consequence of the severe ventilatory limitation.

In conclusion, the physiological and radiographic studies together show that in this patient both extra and intrathoracic airways are diseased but the peripheral airways are unlikely to be involved and the airway resistance is increased due to a diminution of resting calibre as well as to dynamic narrowing on expiration.

Although involvement of the airways in relapsing polychondritis was noted by Hughes $e t$ al. (1972) in $47 \%$ of the reported cases, there have been few assessments of the resulting functional abnormalities or of the underlying pathological changes. The only other extensive physiological study of a patient with relapsing polychondritis of which we are aware is that published by 
Vaudour, Payot, Diebold, and le Melletien (1967). They described a patient with widespread tracheobronchial involvement whose functional pattern bears several similarities to the present case-severe airways obstruction $\left(\mathrm{FEV}_{1} \mathbf{0 . 3 3} 1\right.$., VC 1.71 1.) with FIV $_{1}(0.961$ 1.) greater than the $\mathrm{FEV}_{1}$, a normal residual volume and arterial oxygen saturation. Others have noted a reduced maximum breathing capacity (Pearson et al., 1960 ) or an obstructive ventilatory defect (Horns and O'Loughlin, 1962).

Death in patients with relapsing polychondritis has usually been attributed to respiratory complications (Harwood, 1958; Purcelli, Nahum, and Monell, 1962; Jensen and Jensen, 1967). At necropsy, the affected airway macroscopically shows loss of normal rigidity together with concentric thickening of the wall. Microscopically the lesions resemble those in other cartilaginous tissues. The cartilage plates are degenerate or absent, with infiltration by lymphocytes and plasma cells and replacement by fibrous tissue; sometimes there seem to be areas of regenerating cartilage and bone (Self, Hammarsten, Lyne, and Peterson, 1967) even with foci of haemopoiesis (Verity, Larson, and Madden, 1963). The lesions may be discrete and localized or extensive, involving the whole of the upper airway (Purcelli et al., 1962). Though most attention has been paid to the larynx and trachea, bronchial involvement was recorded in an early case (Altherr, 1936) and has been noted many times since (Verity et al., 1963; Thould, Stansfeld, and Wykeham Balme, 1965; Vaudour et al., 1967). There is, however, no information available on the condition of airways distal to secondary bronchi, and more detailed necropsy studies are needed.

Involvement of the airways in relapsing polychondritis is said to be a bad prognostic sign (Thould et al., 1965; Dolan et al., 1966) often leading to sudden unexpected death. The natural history, however, is variable, and the patient of Vaudour et al. (1967) whose respiratory function was well documented survived three years with severe airways involvement. Other patients with lesions in the airways have lived for up to 24 years (Kaye and Sones, 1964) but it is not clear for how long the airways were affected.

Our patient had been treated with steroids for six months before his respiratory function was first assessed. Between December 1972 and June 1974, when he was seen for reassessment, he continued to lead an active life with no symptomatic deterioration on a daily dose of $10 \mathrm{mg}$ prednisone. Repeat function testing in June 1974 however showed a slight overall deterioration. In particular, the $\mathrm{FEV}_{1}$ had fallen to $0.6 \mathrm{l}$. and there was a further reduction in maximum flow rates at all lung volumes but the pattern remained that of predominantly intrathoracic airflow obstruction; his exercise capacity (in a progressive test) was reduced to $600 \mathrm{kpm} \mathrm{min}{ }^{-1}$; the resting arterial $\mathrm{PCO}_{2}$ was slightly higher at $46 \mathrm{mmHg}$ and during steady state exercise at the same work load as previously $\left(350 \mathrm{kpm} \mathrm{min}^{-1}\right)$ the hypercapnia was more severe $\left(\mathrm{PaCO}_{2} 62 \mathrm{mmHg}\right)$; despite this deterioration the physiological dead space and calculated venous admixture remained normal.

The relapsing nature of the disease implied by its title as well as its comparative rarity make assessment of treatment difficult. Most authorities favour the use of steroids and some (Dolan et al., 1966) say that their efficacy is greatest for laryngotracheobronchial manifestations, but this is difficult to substantiate in the absence of objective tests of ventilatory function. Many of the patients described with tracheal involvement have undergone tracheostomy, and on one occasion (Daly, 1966) a localized segment of the upper trachea was temporarily replaced by a prosthesis with apparent success. Early tracheostomy has been recommended but is likely to benefit only patients with localized tracheal involvement and will be useless in those with more extensive disease. Likewise supportive splinting of the airway might be of value in localized lesions if dynamic effects were predominant. Clearly full radiographic and functional assessment is indicated before any surgical procedure is undertaken.

We wish to thank Professor E. G. L. Bywaters for permission to study the patient and Dr. N. B. Pride 3 . for helpful discussion.

\section{REFERENCES}

Al-Bazzaz, F. and Kazemi, H. (1972). Mechanisms of exercise hypoxemia and dyspnea in tracheal stenosis. American Review of Respiratory $\mathrm{N}$ Disease, 105, 1002.

Altherr, F. (1936). Über einem Fall von systematisierter Chondromalacie. Virchow's Archiv für patho- $\omega$ logische Anatomie und Physiologie und für klinische Medizin, 297, 445.

Bates, D. V., Macklem, P. T., and Christie, R. V. (1971). Respiratory Function in Disease, 2nd ed., p. 2. Saunders, Philadelphia.

Clark, T. J. H. (1970). Inspiratory obstruction. British Medical Journal, 3, 682.

Daly, J. F. (1966). Relapsing polychondritis of the $\frac{\varrho}{\Phi}$ larynx and trachea. Archives of Otolaryngology, $₫$ 84, 570 . 
Dolan, D. L., Lemmon, G. B. Jr., and Teitelbaum, S. L. (1966). Relapsing polychondritis, analytical literature review and studies on pathogenesis. American Journal of Medicine, 41, 285.

Gandevia, B. and Hugh-Jones, P. (1957). Terminology for measurements of ventilatory capacity. Thorax, $12,290$.

Gee, J. B. L., Burton, G., Vassallo, C., and Gregg, J. (1968). Effects of external airway obstruction on work capacity and pulmonary gas exchange. American Review of Respiratory Disease, 98, 1003.

Glynn, L. E. and Holborow, E. J. (1952). Conversion of tissue polysaccharides to auto-antigens by group-A beta-haemolytic streptococci. Lancet, 2 , 449.

Harwood, T. R. (1958). Diffuse perichondritis, chondritis, and iritis. Archives of Pathology, 65, 81 .

Herman, J. H. and Hess, E. V. (1971). Immunopathologic studies in relapsing polychondritis. Abstracts of the 7 th European Rheumatology Congress, 12, 4.

Horns, J. W. and O'Loughlin, B. J. (1962). Tracheal collapse in polychondritis. American Journal of Roentgenology, 87, 844.

Hughes, R. A. C., Berry, C. L., Seifert, M., and Lessof, M. H. (1972). Relapsing polychondritis. Quarterly Journal of Medicine, 41, 363.

Jaksch-Wartenhorst, R. (1923). Polychondropathia. Wiener Archiv für innere Medizin, 6, 93.

Jensen, O. A. and Jensen, F. (1967). Relapsing polychondritis. Acta Pathologica et Microbiologica Scandinavica, 69, 357.

Kaye, R. L. and Sones, D. A. (1964). Relapsing polychondritis. Annals of Internal Medicine, 60, 653.

Leading article (1973). Relapsing polychondritis. British Medical Journal, 2, 627.

McCarthy, D. and Milic-Emili, J. (1973). Closing volume in asymptomatic asthma. American Review of Respiratory Disease, 107, 559.
Miller, R. D. and Hyatt, R. E. (1969). Obstructing lesions of the larynx and trachea; clinical and physiologic characteristics. Mayo Clinic Proceedings, 44, 145.

Pearson, C. M., Kline, H. M., and Newcomer, V. D. (1960). Relapsing polychondritis. New England Journal of Medicine, 263, 51.

Purcelli, F. M., Nahum, A., and Monell, C. (1962). Relapsing polychondritis with tracheal collapse. Annals of Otology, Rhinology and Laryngology, 71, 1120.

Read, D. (1967). Clinical investigation of the regulation of breathing. MD thesis, University of Sydney.

Rebuck, A. S. and Read, J. (1971). Patterns of ventilatory response to carbon dioxide during recovery from severe asthma. Clinical Science, 41, 13.

Self, J., Hammarsten, J. F., Lyne, B., and Peterson, D. A. (1967). Relapsing polychondritis. Archives of Internal Medicine, 120, 109.

Spiro, S. G., Hahn, H. L., Edwards, R. H. T., and Pride, N. B. (1975). Analysis of the physiological strain of submaximal exercise in patients with chronic obstructive bronchitis. Submitted for publication.

Thould, A. K., Stansfeld, A. G., and Wykeham Balme, H. (1965). Chronic atrophic perichondritis. Annals of Rheumatic Diseases, 24, 563.

Vaudour, X., Payot, J., Diebold, J., and le Melletien, J. (1967). Les manifestations respiratoires de la polychondrite chronique atrophiante. Journal Français de Médicine et Chirurgie Thoraciques, 21, 383.

Verity, M. A., Larson, W. M., and Madden, S. C. (1963). Relapsing polychondritis. American Journal of Pathology, 42, 251.

Requests for reprints to: Dr. G. J. Gibson, Department of Medicine, Royal Postgraduate Medical School, Hammersmith Hospital, London W12. 